\title{
Application of fine-grained binding materials in technology of hardening backfill construction
}

\author{
O. Kuzmenko \& M. Petlyovanyy \\ National Mining University, Dnipropetrovs'k, Ukraine
}

A. Heylo

LLC “Krasnolimans'ke”, Rodins'ke, Ukraine

\begin{abstract}
The expediency of differential formation of high filling massif chambers based on a developed technology with usage of fine-grained binding materials. Two-stage grinding circuit domain of granulated slag and limestone to produce fine particles, allowing to improve the structural and mechanical properties of filling massif, increase the proportion of rocks in mixture and reduce material consumption by $25-75 \%$ are considered.
\end{abstract}

\section{INTRODUCTION}

Annually underground mining of ore deposits penetrates deeper into the Earth's interior, leading mining in complex geological conditions, applying a hardening stowing chambers. This ensures completeness recess ore with minimum losses and mining safety, reduced environmental pressures on industrial region. Flow diagrams for filling mixtures and their components, as well as equipment for grinding raw material, have not been significant transformation since introduction of this method of rock pressure control. And it's despite the fact that there is a constant decrease in the depth of mining and increases the economic component for the purchase of filling materials. To reduce the cost of filling operations, in hardening backfill add crushed rock from underground development.

To increase the strength of artificial local massif of stress concentration arising at the individual elements of the chambers in the filling mixturecomprising increasing proportion of cement. Under the conditions of intensive mining operations and manifestations of rock pressure, and the use of massif explosions necessary mechanical properties achieved by increasing the flow of cement in filling mixture is not always possible. Partial collapse of the filling massif to the chamber in the second stage of mining floor leads to the contamination of the ore massif. Increases of filling operations costs and risks associated with downtime due to hardening of mixture in pipes, their mounting/dismounting works.
One of the ways to improve the curable compositions of backfill is mechanical or chemical activation of components of backfill (Voloschenko 1985). It was established that dispersion state in the curable binder system affected on density and porosity of the stone monolithic: it increases with increased density, reduced porosity, increase in strength occurs. Mechanical activation was seen as setting a two-stage grinding circuit binder.

At present time in underground mines CIS technology of filling operations provides single-stage crushing circuit binder to give the final product particle size of $50-60 \%$ of the particles $-0.074 \mathrm{~mm}$, which corresponds to a specific particle surface $2000 \mathrm{~cm}^{2} / \mathrm{g}$ with an average diameter of $35-40 \mathrm{mi}-$ crons.

Application in stowing mixtures of materials possessing binding properties or inert solve a number of issues, but have limited opportunities because of insufficient knowledge of interaction of chemical elements mixed with water according to disclosure of relationships and particle surface. Here is a powerful energy potential, which could give a considerable addition of strength artificial massif generated by the internal connections of different mode of action upon the application of external loads.

Technological direction on strength increasing of created artificial massif is in renewal stage of, but has a great scientific and practical importance, because at large volumes of filling operations decreasing of prime cost and improving of filling massif quality becomes actual issue. 


\section{MAIN MATERIAL OF RESEARCH}

The criterion for technological schemes development of fine binder specific surface 2800, 4300, $5500 \mathrm{~cm}^{2} / \mathrm{g}$ serves ultimate size of the product. Particles studied compositions of filling mixtures of size 15 microns have a maximum specific surface area $5500 \mathrm{~cm}^{2} / \mathrm{g}$ In terms of technological schemes of filling complexes mines CIS achieve specified product size is only possible by improving the grinding circuit. The advantage of hardening compositions developed by the authors based on backfill fine particles along with high strength is the development of forms of internal structures in the artificial massif. Its hardness increases, reduces consumption of blast furnace slag by $25-75 \%$ and increases share-part mixed breed. Under laboratory conditions, Zaporizhzhya iron plant (ZZHRK) studies have been conducted on the impact of highly blast-furnace slag and limestone flux $\left(S_{s p}=2000\right.$ $6600 \mathrm{~cm}^{2} / \mathrm{g}$ ) on the strength and rheological properties of filling mixtures. Considered structural changes occurring at different filling massif particles dispersed state.

It has been established that experimental values of the specific surface of particles are slightly different from theoretical. This is due to a variety of physical and mechanical properties of crushed materials. Analysis of the distribution of particle size fractions of blast-furnace slag as a main binder per unit is realized on device Multisizer-3 and the results are shown on Figure 1. Rounding actual specific surface of blast furnace slag, resulting in changing steps $2000,2800,4300,6600 \mathrm{~cm}^{2} / \mathrm{g}$. The maximum increase in the specific surface area compared to the traditional (ZZHRK) was 3.3 times.

Increase of the specific surface of the particles results in a reduction of their diameter, which is necessary for the hardening of filling massif. When the specific surface area of the slag $2000 \mathrm{~cm}^{2} / \mathrm{g}$ up to $50 \%$ of the particles are in the inert state, without forming new compounds. Starting with a specific surface of $4300 \mathrm{~cm}^{2} / \mathrm{g}$ all particles completely react with water molecules involved in the formation of the structure and form strong bonds in the backfill massif. Aggregates of ultrafine grinding lend out scatter fractions, whereas there are ball milling fractions of from 4 to 100 microns. To maximize the effectiveness of finely ground blast furnace slag is necessary to cut down shredder scatter particles.

Distribution histograms of class fractions of slag and limestone found between average particle diameter and specific surface, which is shown on Figure 2. Using representation of dependencies it is possible to predict the average particle diameter at a different specific surface area of the slag. (a)

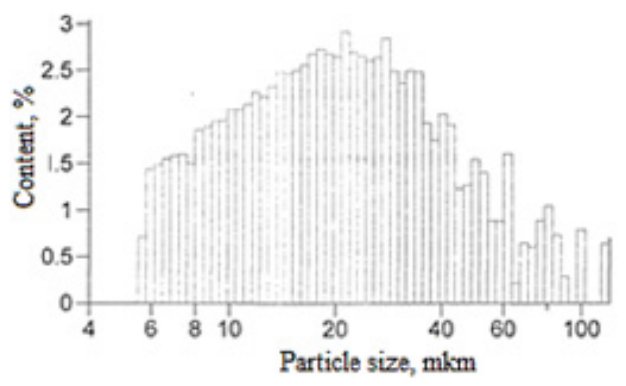

(b)

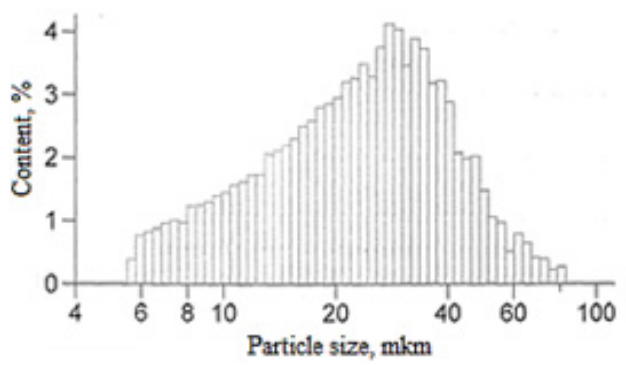

(c)

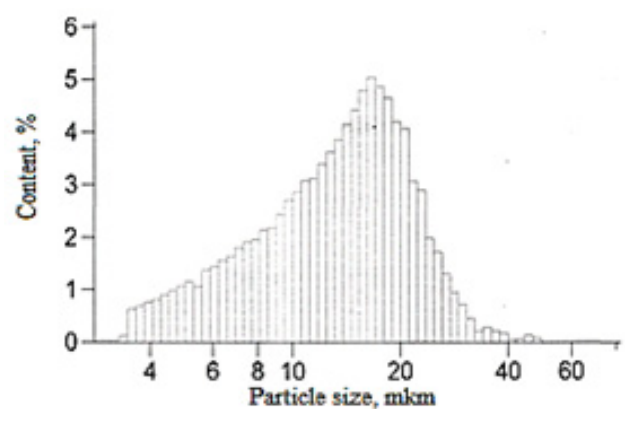

(d)

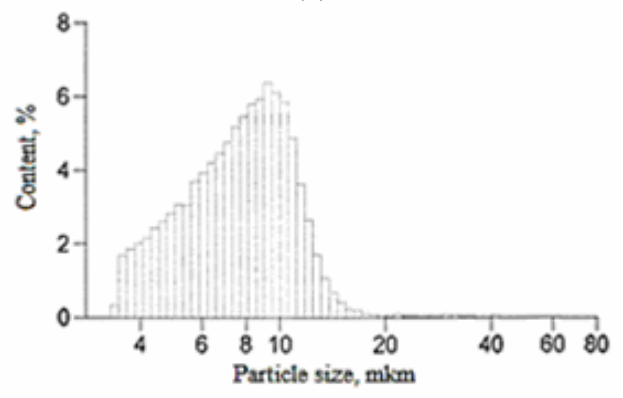

Figure 1. Histograms factions in the blast-furnace slag with (a) $S_{s p}=1999(2000) \mathrm{cm}^{2} / \mathrm{g} ; D=35$ microns; (b) $S_{s p}=$ $2831(2800) \mathrm{cm}^{2} / \mathrm{g}, D=26$ microns; (c) $S_{s p}=4258.8$ (4300) $\mathrm{cm}^{2} / \mathrm{g}, D=14.5$ microns; (d) $S_{s p}=6592.8$ (6600) $\mathrm{cm}^{2} / \mathrm{g}, D=8.2$ microns. 


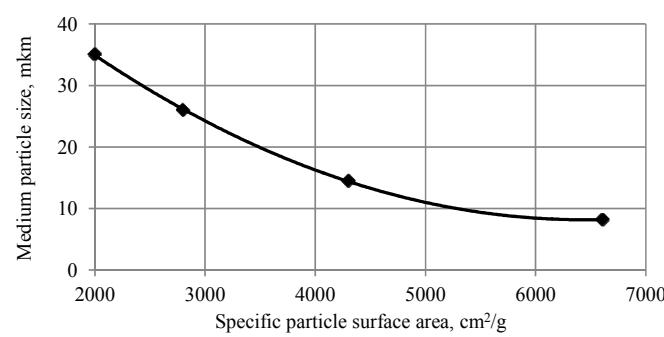

Figure 2. Interconnection average diameter and specific surface area of particles of blast furnace slag.

The results showed the effect of specific surface area increasing of the slag and limestone composition of filling mixture to improve the quantitative and qualitative characteristics of artificial massif. Zaporizhzhya iron ore plant in hard mine-geological conditions develops rich in hematite-martite ores of South Belozersky deposit (Fe content $>60 \%$ ) Num- ber of floors-camera system development with sublevel ore breaking deep wells and then filling goaf hardening mixture. Difficult conditions are defined at the top of occurrence of ore-crystalline massif aquifers unstable rocks hanging wall of the fortress with a coefficient scale prof. M.M. Protodyakonov $f=4-8$, depth development (330-940 m), fracture massif. These factors lead to increased demands on the strength of filling massif. Actual dumped filling massif to chamber was observed in the middle and sides of the camera connection areas with its roof. Composition of filling mixture as follows: granulated blast furnace slag $-18.1 \%$, flux production waste $-47.5 \%$, the breed $-16.3 \%$, water $-18.1 \%$.

For full disclosure of binding properties of granulated blast furnace slag and flux of the waste production as well as improve the structural strength properties of filling massif proposes the use of twostage crushing circuit (Figure 3).

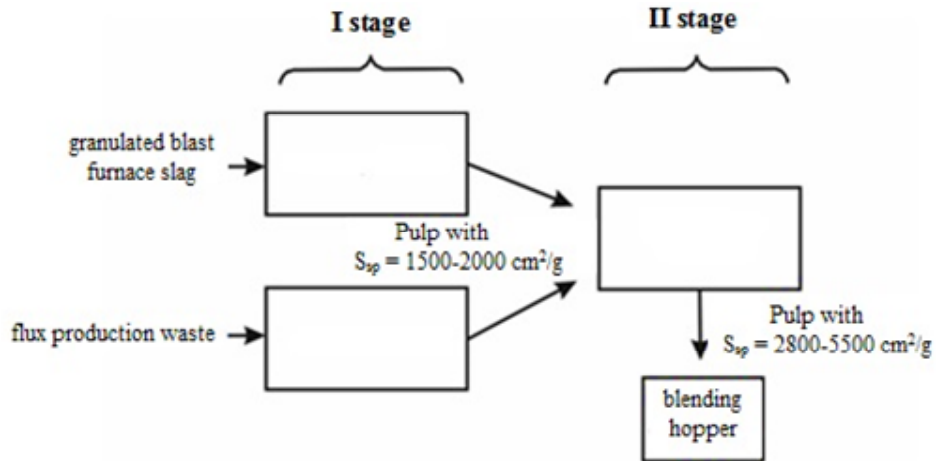

Figure 3. Two phase slag and limestone grinding for preparing curable backfills.

Chamber filling technology involves usage of filling mixture with varying amounts of binders to ensure durability artificial massif in a weakened field (bottom, location sublevel workings). Actually, it provides differentiation distribution strength in technological features. Instead expensive binder (Portland) technology is proposed differential chambers filling mixture for the production of fine filling operations, but with varying degrees of grinding. Depending on the size of the camera, the amount of sublevel openings in the chamber, as well as the number of daily flow chambers filled grinding slag and limestone in an amount will vary. For conditions ZZHRK need to fine mixture will be approximately 1150 tons/day. Ball mill MSHTS-36-55 number one source produces pre-grinding (up to 10 $\mathrm{mm}$ ) fractions of granulated blast furnace slag, a ball mill number 2 - grinds fluxing limestone $(50 \%$ of the flow of slag). In its usual form used size up to $5 \mathrm{~mm}$ as an inert filler to activate binding properties. Components tabs $55-60 \%$ are brought to a particle size class of $-0.074 \mathrm{~mm}$, which corresponds to a specific surface of $2000 \mathrm{~cm}^{2} / \mathrm{g}$ further crushed slag and limestone slurry received in the second stage mill. The second stage provides regrinding slag and limestone to the desired fineness. In our case, the specific surface area is required variation of slag and limestone within three modes $2800,4300,5500$ $\mathrm{cm}^{2} / \mathrm{g}$ for the formation of the necessary structural formations in filling massif.

For reliable quality control of pulp consisting of ultrafine fractions are encouraged to use the grain analyzer Multisizer-3. It allows for a short period of time (up to $5 \mathrm{~min}$ ) obtaining the distribution diagram class fractions of crushed material with high reliability. With the construction of filling massif in 
the first stage of the chambers mining ore reserves recommended $65 \%$ of the total mixture to fill a specific surface area of binder $2800 \mathrm{~cm}^{2} / \mathrm{g}$ (the space between the sublevel) $30 \%$ (sublevels, reinforcing layers) $-4300 \mathrm{~cm}^{2} / \mathrm{g}, 5 \%$ (bottom) $-5500 \mathrm{~cm}^{2} / \mathrm{g}$. Application of two-step milling scheme reduces fuel cost blast-furnace slag. So for the chamber with a volume of 110 thousand $\mathrm{m}^{3}$ level $840-940 \mathrm{~m}$ ZZHRK amount crushed binder decreases from 61.600 to 39.600 tonnes, or 1.55 times. Differentiated filling chamber with backfill by different specific surface makes ultrafine grinding process effective, since the volume of the chamber gob finely slag amount $\left(4300-5500 \mathrm{~cm}^{2} / \mathrm{g}\right)$ is negligible.

Completed studies of dispersion effect on the properties of binder filling mixture showed that the promising direction of development is usage of filling works of fine grinding. This is achieved by using a new technological level mills type Vertimill, SMD (USA) and IsaMill (Australia) in the circuit grinding apparatus filling mixture in the mining industry over the past decade. They refer to the ball and pebble mills, but have fundamentally different physical and kinematic basis achieve the desired class crushing.

In the process of preparation of the complex chain of stowing hardening backfill based on fine particle binding recommended IsaMill M3000, with sufficient capacity (up to $100 \mathrm{t} / \mathrm{h}$ ), the possibility of achieving the final product size to 5 microns $\left(6000 \mathrm{~cm}^{2} / \mathrm{g}\right)$.

In order to provide an adequate economic assessment should be guided grinding energy performance depending on the size of the output product (Stirred milling technology....). In this paper, noted that with increasing fineness varies the percentage of passing particles and the specific energy consumption. The feed material to the mill in the experiment has IsaMill fineness grade of $60 \%-0.08 \mathrm{~mm}$ particles, which in general corresponds fineness ball mill under the conditions of the packing ZZHRK complex. Based on the indicative timetable obtain specific energy costs three modes in the second stage grinding unit cost of grinding to $S_{s p}=2800 \mathrm{~cm}^{2} / \mathrm{g}-$ $19 \mathrm{~kW} / \mathrm{t}, S_{s p}=4300 \mathrm{~cm}^{2} / \mathrm{g}-33 \mathrm{kWh} / \mathrm{t}, S_{s p}=5500$ $\mathrm{cm}^{2} / \mathrm{g}-45 \mathrm{kWh} / \mathrm{t}$.

Costs for slag grinding in ball mills stowing complex "ZZHRK" is $15 \mathrm{~kW} / \mathrm{t}$. As a result of lower fuel chamber slag ball mill load the first stage is reduced, which would entail a reduction of energy consumption. These control fineness stowing complex show a wide variation in producing particles of size $-0.074 \mathrm{~mm}$ from 46 to $57 \%$. To receive uniform in size with ball milled slag grinding is problematic. This factor has a direct influence on the formation of filling massif with uniform strength, which is possible under the same terms of dispersion of slag and constant chemical composition.

Despite the fact that for two-stage binding circuit increases the specific power consumption by reducing the flow of blast furnace slag at the camera at the final cost of one-and two-stage grinding scheme will differs slightly.

To calculate the economic impact of proposed recommendations we compared two versions of cooking hardening backfill with a single-stage (base case) and two-step (recommended) grinding binder. The main criterion of economic efficiency cost of components adopted hardening backfill as the cover story in the production costs and the cost of filling works on energy grinding binder.

In the basic version the spent an average of 110 camera thousand $\mathrm{m}^{3}$ is filled to a height of $130 \mathrm{~m}$ with a flow of blast furnace slag $560 \mathrm{~kg} / \mathrm{m}^{3}$ (including moisture) when the specific surface area of up to $2000 \mathrm{~cm}^{2} / \mathrm{g}$, fluxing limestone $-950 \mathrm{~kg} / \mathrm{m}^{3}$, rock $-550 \mathrm{~kg} / \mathrm{m}^{3}$.

In preferred variant, the total volume of chamber is filled with a hardening backfill specific surface area of the blast furnace slag and limestone $(50 \%$ of the flow of slag) $2800 \mathrm{~cm}^{2} / \mathrm{g}-70$ thousand $\mathrm{m} 3,4300$ $\mathrm{cm}^{2} / \mathrm{g}-34$ thousand $\mathrm{m} 3,5500 \mathrm{~cm}^{2} / \mathrm{g}-6$ thousand $\mathrm{m}^{3}$ of filling mixture composition: blast furnace slag $240 \mathrm{~kg} / \mathrm{m}^{3}$, ground limestone $-110 \mathrm{~kg} / \mathrm{m}^{3}$, limestone $-1050 \mathrm{~kg} / \mathrm{m}^{3}$, the breed $-650 \mathrm{~kg} / \mathrm{m}^{3}$.

Backfill materials and energy costs at base and preferred variant will be $92.3 \mathrm{UAH} / \mathrm{m}^{3}$ and 88.9 $\mathrm{UAH} / \mathrm{m}^{3}$. During usage of the technological recommendations, costs of filling works of cleaning chamber on the first stage on materials and energy could be reduced to $3.9 \%$. With increasing strength of filling massif up to $10 \mathrm{MPa}$ (traditional $7.5 \mathrm{MPa}$ ) at the age of 180 days increases its resistance to outcropping and ore dilution rates are dropping from 4.5 to $1.8 \%$ (Figure 4 ).

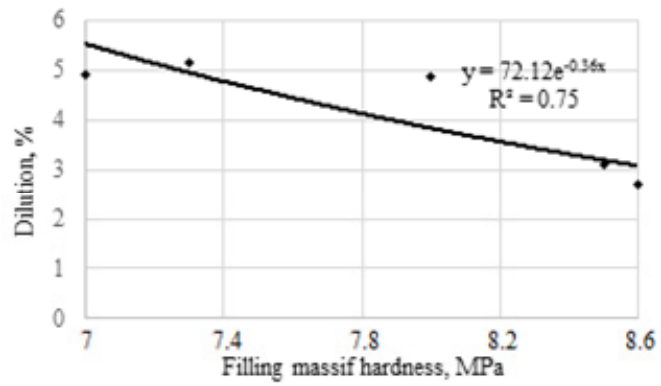

Figure 4. Dependence of dilution during ore chambers mining of second stage from backfill hardness.

Loss from falling $1 \%$ backfill material is accompanied by decrease in iron content of mined ore is 
equal to $28 \mathrm{UAH} / \mathrm{t}$. Additional economic benefit from reduced dilution is $2.7 \cdot 7.2=19.44 \mathrm{UAH} / \mathrm{t}$.

\section{CONCLUSIONS}

1. Technology for differential filling chambers of the first stage of filling mixture with a specific surface binder $2800 \mathrm{~cm}^{2} / \mathrm{g} 65 \%$ of its volume (the space between the sublevel) $30 \%$ (sublevels, reinforcing layers) $-4300 \mathrm{~cm}^{2} / \mathrm{g}, 5 \%$ (bottom) $-5500 \mathrm{~cm}^{2} / \mathrm{g}$. This will relieve the outcrop filling massif height and form a filling massif - needled fibrous structure in the zones of tensile stresses on the contour extraction chambers, as well as layered lamellar structure under compressive stresses.

2. Two-stage circuit grinding granulated blast slag and limestone waste, allowing reducing their consumption by $25-75 \%$, improving the structural and mechanical properties of filling massif and increas- ing the proportion of mixed breed. The first stage is represented by ball mills, the second stage of the ultrafine grinding mill series IsaMill (Australia).

3 . The economic estimation of the proposed recommendations filling high chambers and hardening filling massif, which will be about $3.4 \mathrm{UAH} / \mathrm{m}^{3}$ of mixture and $19.44 \mathrm{UAH} / \mathrm{t}$ of ore mined from the reduction of its dilution is given.

\section{REFERENCES}

Voloschenko, V.P. 1985. Geomechanical basis for development of iron ore deposits powerful systems with a backfill: Abstract of dis. Doctor. Tech. Scien., Dnipropetrovs'k: 314.

Stirred milling technology: http://myxps.ca/EN/ Presentations/Documents/xps_speech_0905112_mcgill_Seminar. $p d f$ 
